\title{
The Walking Dead: sobrevivencialismo, corpo sem órgãos e comunidade das singularidades nômades
}

\section{Eduardo Yuji Yamamoto}

\section{Resumo}

A partir da proposta teórico-metodológica de Douglas Kellner (o mapeamento do presente pelo futuro), analisa-se 0 seriado de TV The Walking Dead (2010-2015...), enquanto suporte discursivo de uma tensão subjetiva nas culturas midiatizadas a partir dos EUA. Duas premissas subsidiam este trabalho: a indissociabilidade entre a cultura midiatizada e as práticas sociais contemporâneas; e a presença de regimes divergentes de sociabilidade nessa cultura: fechar-se à profusão vinculativa da atualidade ou expor-se à experimentação subjetiva. Para auxiliar a análise, utiliza-se o conceito de "corpo sem órgãos", de Artaud, Deleuze e Guattari.

\section{Palavras-Chave}

Cultura da Mídia 1. Filosofia Zumbi 2.

Análise do Discurso 3.
Eduardo Yuji Yamamoto I yujieduardo@gmail.com Doutor em Comunicação pela Universidade Federal do Rio de Janeiro (ECO/UFRJ). Professor Adjunto e pesquisador da Universidade Estadual do Centro-Oeste (Unicentro).

\section{Introdução}

"E se somente estivermos realmente vivos se nos comprometermos com uma intensidade excessiva que nos coloca além da 'vida nua'? $\mathrm{E}$ se, ao nos concentrarmos na simples sobrevivência, mesmo quando é qualificada como 'uma vida boa', o que realmente perdermos for a própria vida?"

Slavoj Zizek

Passada a onda dos alienígenas e dos vampiros, a indústria norte-americana do audiovisual parece agora apostar as suas fichas nos zumbis. A figura do morto-vivo, do animal que ressuscita e vagueia pelas cidades sob trapos à procura de carne humana, por incrível que pareça, tem agradado públicos dos EUA e de muitos outros países, estabelecendo um universo ficcional à parte: fãsclubes, blogs de discussão, revistas especializadas, manifestações artístico-culturais, etc.

Para 0 teórico da mídia Douglas Kellner, 0 súbito interesse pelo zumbi, atualmente, não deve ser encarado como mais uma futilidade vazia e desconexa capitaneada pela indústria do entretenimento, mas como um índice da vida 
social contemporânea, já que, por trás de sua mera insurgência, estão referências simbólicas importantes da cultura.

\section{A investigação feita por Kellner sobre a} popularidade mundial dos filmes norte-americanos de terror dos anos 1980 - segundo ele, associada ao clima de recessão social dos países do 0cidente, uma sintonia com o inexplicável (o sumiço repentino da estabilidade anteriormente existente) - tem por base a premissa anterior e serve-nos aqui como pista para a investigação deste zombi revival. Busca-se, neste caso, evidenciá-lo a partir de sua formação discursiva, isto é, do atual contexto de instabilidade em que atravessam os países ocidentais, em especial os EUA, associando a emergência do morto-vivo a este momento de grande incerteza - possibilidade de perda de sua hegemonia frente às alianças políticas, econômicas e militares do Oriente -; ou então, e em uma dimensão mais profunda, com a decadência irreversível de instituições como a família, o Estado, Deus etc., que outrora serviam como lastros metafísicos que davam sentido para as suas existências.

[...] o melhor modo de desenvolver teorias sobre mídia e cultura é mediante estudos específicos dos fenômenos concretos contextualizados nas vicissitudes da sociedade e da história contemporâneas. Portanto, para interrogar de modo crítico a cultura contemporânea da mídia é preciso realizar estudos do modo como a indústria cultural cria produtos específicos que reproduzem discursos sociais encravados nos conflitos e nas lutas fundamentais da época (KELLNER, 2001, p. 12).
A premissa da qual parte este trabalho é de que 0 seriado de TV The Walking Dead (TWD), que traz como pano de fundo o apocalipse, reproduz um discurso social da presente época, qual seja, a tensão entre uma vida de amplas relações e a insegurança psicológica proveniente de tal sociabilidade.

Sobre o fenômeno TWD, a literatura dispõe hoje de estudos com enfoques variados, desde os históricos (que recuperam o gênero em George Romero, no famoso Night of the Living Dead, de 1968), os sociológicos (os quais denunciam os aspectos negativos do consumo, na correlação dos zumbis com a massa urbana alienada), os transmidiáticos (que problematizam o modelamento da série em suportes diferentes: impresso, TV, games, etc.), e os discursivos (que evidenciam conjuntos tensivos e engendramentos semânticos na construção de sentido, como é caso deste trabalho). Esses estudos não se excluem, mas desenham um espaço promissor para reflexões sobre a sociedade capitalista e seus dramas existenciais. Não sem motivo que o pensador espanhol Jorge Fernández Gonzalo tenha destinado um território cognitivo específico ao tema: filosofia zumbi.

Por essa expressão, Gonzalo não pretende institucionalizar um objeto ou campo de pesquisa, nem sistematizar "0 fenômeno histórico-cultural do zumbi em sua implicação com o cinema e outras artes, muito menos oferecer uma leitura moral ou paródica do estilo 
e das narrações icônicas prediletas do gênero".

Do contrário,

Trata-se de conceber uma filosofia zumbi, de autorizar o zumbi como conceito, como metáfora a partir de onde se possa entender 0 entorno mediatizado que nos rodeia: desequilíbrios financeiros, paixões reduzidas ao pastiche de sua expressão hiper-real, modelos de pensamentos arraigados pelo poder e consolidados na implementação da maquinaria capitalista (GONZALO, 2011, p. 11)

No presente texto, o zumbi desempenha a metáfora do agenciamento, 0 inumano ou impessoal. Concebê-lo dessa maneira autoriza-nos a ler TWD a partir de uma crise de sociabilidade que atravessa 0 0cidente americanizado ${ }^{1}$, e que dispõe os seus viventes em um limiar subjetivo (como veremos, avançar ou recuar este limite implicaria decidir-se sobre duas posturas sociabilizantes: vincular ou não com as diferenças, com o desconhecido).

A incubação do vírus-zumbi no indivíduo dito saudável ou normal, a derradeira mordida que esvazia o sujeito e o transforma, tal como nos apresenta a série televisiva, constituem boas metáforas para pensar o agenciamento e os processos que 0 engendra: morte subjetiva, processos silenciosos de derivação (sobreposição de duplos, desdobramentos, ramificações), etc.
0 caráter desolador deste evento catastrófico - 0 apocalipse zumbi - ganha ares de pessimismo naqueles que buscam formas previsíveis de vida e relação. Outra possibilidade é de que a atmosfera desértica atribuída a esse evento insere seus viventes em um topos neutro, abrindo-os a uma deriva relacional infinita. Contudo, vê-lo em sua plenitude positiva é tão perigoso quanto conjurálo em nome da segurança. Cai-se, neste caso, em uma mesma armadilha.

Daí a importância de um "corpo sem órgão" lançado aqui para dar operacionalidade aos agenciamentos. Criar para si um corpo sem órgãos, tal como ensinam Gilles Deleuze e Felix Guattari (1996), implica saber contraefetuar 0 zumbi e o próprio apocalipse; viver não como vítima, penitente, misantropo ou sobrevivente nesse platô de intensidade contínua e variada, mas como estilista de si: nem o corpo esvaziado de um zumbi, nem obsessivo do padre; tampouco o corpo canceroso do Governador.

\section{Cultura da Mídia}

A expressão "cultura da mídia" integra o léxico dos principais conceitos dos estudos de comunicação e cultura midiatizada. Por essa expressão, Kellner

A expressão "Ocidente americanizado" refere-se a uma formação discursiva presente na formação social dos EUA, mas também em diversas outras formações que fazem uso dos mesmos textos culturais norte-americanos. Isso decorre, principalmente, da exportação, em larga escala, de bens simbólicos norte-americanos a variados países (inclusive do Oriente), os quais passam a urdir o tecido de sua vida cotidiana com elementos da cultura norte-americana. As novas "formas de popular global", referidas por Kellner (2001, p. 14), definem, em cada formação social ocidentalizada, uma formação discursiva que comporta, em sua heterogeneidade, uma estrutura mínima de organização (mesmo, às vezes, em contradição com elementos da cultura local). A análise aqui, entretanto, refere-se a essa estrutura mínima discursiva, e não o seu hibridismo com outras culturas. 
observa a reciprocidade entre os textos culturais veiculados pelos meios de comunicação (jornais, revistas, TV, blogs) e a produção de subjetividades (individuais e coletivas).

Há uma cultura veiculada pela mídia cujas imagens, sons e espetáculos ajudam a urdir o tecido da vida cotidiana, dominando o tempo de lazer, modelando opiniões políticas e comportamentos sociais, e fornecendo o material com que as pessoas forjam sua identidade [...] As narrativas e as imagens veiculadas pela mídia fornecem os símbolos, os mitos e os recursos que ajudam a constituir uma cultura comum para a maioria dos indivíduos em muitas regiões do mundo de hoje. A cultura veiculada pela mídia fornece 0 material que cria as identidades através das quais os indivíduos se inserem nas sociedades tecnocapitalistas contemporâneas, produzindo uma nova forma de cultura global (KELLNER, 2001, p. 09).

Desse conceito, extraímos três ideias-chave para a construção teórico-conceitual do presente texto: 1) a hegemonia norte-americana na estruturação de uma cultura da mídia globalizada; 2) a participação de diferentes públicos nessa cultura; 3 ) a presença de dois modos de sociabilidade em seu interior.

Embora sejam justas as críticas de teóricos da comunicação ao que parece ser uma unilateralidade comunicativa nessa primeira ideia, argumentamos a sua pertinência a partir da relação econômica (produção, consumo e circulação de produtos culturais) e discursiva estabelecida pelos EUA junto aos chamados países capitalistas ocidentais. Utiliza-se, neste caso, 0 conceito gramsciano de hegemonia para indicar uma posição de predominância discursiva (mais do que numérica), garantida por dispositivos e instituições norte-americanas de poder que operam em âmbito transnacional.

Tal cultura hegemônica, observa Kellner, opera de modo conciliador com as diferentes formações sociais por ela abrangida. Portanto, estabelecer uma conexão entre a popularidade de certas produções com as manifestações culturais dessas mesmas formações faz-se pertinente, desde que assim se equacione 0 sentimento de pertença (e representação) do público com tais conteúdos.

"Participação", diz Kellner (2001, p. 11), é 0 fator decisivo capaz de produzir tal conexão, pois à medida que os indivíduos modelam e são modelados por essa cultura, quer dizer, participam ativa e passivamente da ressignificação desse imaginário (constituindo, neste caso, a sua própria identidade), acabam por estabelecer uma relação com a vida dos personagens da ficção.

[...] entender o porquê da popularidade de certas produções pode elucidar 0 meio social em que elas nascem e circulam, podendo, portanto, levar-nos a perceber o que está acontecendo nas sociedades e culturas contemporâneas (KELLNER, 2001, p. 14).

Correlativa à situação de muitas formações sociais, sobretudo em vista da dinâmica desterritorializadora do capitalismo atual, destacamos o nomadismo de TWD: diásporas forçadas ou voluntárias, constituição de comunidades múltiplas, consumação da vida em regimes narrativos ou existenciais, etc. 
Tal nomadismo referencia-se em audiências variadas unificadas por uma mesma dinâmica econômica e cultural - a globalização -, que expõe a tensão entre dois regimes de sociabilidade, qual seja, 0 tradicional, voltado à manutenção e ao aperfeiçoamento de instituições clássicas de vinculação, tais como a família, o Estado, os partidos políticos, etc; e o contemporâneo, o qual se apresenta tanto a partir de uma crítica à tradição - entendida como limitadora e totalitária -, quanto na proposição de formas de sociabilidade para além das relações estáveis do matrimônio, do círculo das amizades íntimas, das alianças institucionais, heteroafetivas e partidárias, a exemplo das recentes performances públicas da multidão.

0 modo de sociabilidade chamado aqui de tradicional refere-se ao investimento da ação sociabilizadora do sujeito à "própria base de reprodução do sistema", como propõe Anthony Giddens (1991, p. 45) em seu conceito de reflexividade social. Assim, se a vida moderna, como afirma Giddens, tem consistido "no fato de que as práticas sociais são constantemente examinadas e reformadas à luz de informação renovada sobre estas próprias práticas, alterando assim constitutivamente seu caráter", tal alteração seria apenas parcial devido não só aos sistemas ditos "tradicionais" (vistos por Giddens como empecilhos ao desenvolvimento do sujeito), mas também às próprias instituições modernas, cujas ações reflexivas, como o próprio nome diz, voltar-se-iam para si, para a reforma institucional e não para sua consumação. Diversamente, sua plena expressão, no sentido de uma liberação subjetiva radical, somente realizar-se-ia por meio de um gesto de subjetivação contemporânea: sua intensificação. 0 contemporâneo aqui é utilizado não como sinônimo de atual ou tempo presente, mas, conforme Giorgio Agamben (2009, p. 58), desacordo crítico e visionário com o tempo e as ações reativas, automáticas e reprodutivistas de então: "Pertence verdadeiramente ao seu tempo, é verdadeiramente contemporâneo, aquele que não coincide perfeitamente com este". 0 modo de sociabilidade contemporânea, neste caso, apresentar-se-ia não nos regimes de subjetivação autocêntricos ou reflexivos (diga-se seguro) da família ou da comunidade, mas em sua fragmentação, no aberto de seus rompimentos.

A emergência opositiva desses dois modos de sociabilidade tem comparecido em muitos documentos sociológicos ${ }^{2}$, tal como 0 estudo de Richard Sennett sobre a presença pública dos indivíduos nos espaços urbanos. Segundo ele, a partir do começo do século XIX, em muitas cidades do mundo, consolidou-se uma forma de apresentação pública baseada na estabilidade subjetiva. Essa forma social, denominada "comunidade de personalidade coletiva", privilegiou a segurança psíquica e as enunciações pessoais da substância comum (figurada em 
líderes carismáticos), em detrimento do caráter impessoal que, conforme ele, caracterizaria 0 espaço público e as experiências socializantes.

0 que emerge nos últimos cem anos, quando comunidades de personalidade coletiva começaram a se formar, é que o imaginário compartilhado se torna um freio à ação compartilhada. Do mesmo modo como a própria personalidade havia se tornado uma ideia anti-social, a personalidade coletiva se torna identidade de grupo em sociedade hostil e difícil de se traduzir em atividade de grupo (SENNETT, 1995, p. 276).

De acordo com Sennett, essa forma social hegemônica, entendida como modo de sociabilidade (logo, também como experiência de si) tradicional, inverteu o princípio de civilidade - a ideia de público enquanto participação das diferenças - ao ressignificá-lo pela exclusão das experiências sociais desestabilizadoras desses imaginários compartilhados.

A recusa em enfrentar, assimilar e explorar a realidade exterior à escala paroquiana é, num certo sentido, um desejo humano universal, enquanto simples medo do desconhecido. 0 sentimento de comunidade formado pelo compartilhar de impulsos tem o papel especial de reforçar o medo diante do desconhecido, convertendo a claustrofobia num princípio ético (IBIDEM, p. 378).

0 crescimento de "cadeias de bairrismos" e a disseminação do direito de "sermos deixados em paz", ou de nos associarmos livremente para protegermo-nos dos estranhos, como observa Sennett, hoje têm se chocado com os enunciados publicitários da solidão temerária. Nesse espaço tensivo em que prospera a sociedade de consumo, diz Zygmunt Bauman (2003, p. 10), o sujeito atual vê-se, assim, dividido: "Não seremos humanos sem segurança ou sem liberdade; mas não podemos ter as duas ao mesmo tempo e ambas na quantidade que quisermos".

\section{Corpo sem órgãos}

A expressão "corpo sem órgãos" (Cs0) constitui uma das metáforas filosóficas mais poderosas da obra de Deleuze e Guattari contra as produções daquilo que os filósofos chamam de filosofia da representação ou do mesmo. A expressão aparece inicialmente no livro 0 anti-édipo (1972), sendo retomada anos mais tarde no $6^{0}$ platô, " 28 de novembro de 1947 - como criar para si um corpo sem órgãos", em referência à transmissão radiofônica de Antonin Artaud "Para acabar com 0 juízo de Deus".

De maneira estratégica, Deleuze e Guattari (1997) apresentam sete eixos de tematização do Cs0, cujas intersecções permitem evidenciálo: 1) a emergência conceitual do Cs0 como performance e não como expressão; 2) uma crítica ao saber psicanalítico mediante a qual o $\mathrm{Cs} 0$ voltar-se-ia contra as aspirações interpretativas do Eu, em prol da experimentação (perspectiva esquizoanalítica); 3) o desenvolvimento do Cs0 no âmbito da filosofia, aproximando-o de conceitos como "campo da imanência", "plano de consistência" e "spatium"; 4) a disputa entre o organismo e o Cs0 pelo domínio do corpo, isto é, das produções biológicas e subjetivas; 5) 
a observação do Cs0 em âmbitos variados do

cotidiano (nas práticas do masoquista e do viciado, no governo de si, no amor cortês, na escritura, etc.); 6) a tipificação do Cs0 (pleno, vazios, cancerígenos); 7) prudência ou aconselhamento sobre os modos de criação de um CsO.

Para as finalidades deste texto, não desenvolveremos cada um desses eixos de tematização do Cs0, mas os trabalharemos transversalmente, de modo que tais incursões evidenciem os referidos regimes de sociabilidade divergentes.

Diferentemente de "cultura da mídia", o Cs0 não é um conceito, mas, como argumentam Deleuze e Guattari, "uma prática, um conjunto de práticas". Com essa afirmação, os filósofos buscam tanto desvencilhar-se da armadilha linguística, que confere significado à ideia (embora à custa de seu aprisionamento substancialista), quanto enfatizar a experimentação e realização indeterminada que se reduziria, em termos de intensidade e singularidade, à substância significante (conceito): "Ao Corpo sem Órgãos não se chega, não se pode chegar, nunca se acaba de chegar a ele, é um limite. Diz-se: que é isto - o Cs0 - mas já está sobre ele" (DELEUZE; GUATTARI, 1996, p. 09).

A concepção do Cs0 como prática, por outro lado, libera-o a uma experiência ontologicamente originária, isto é, do campo intensivo e impessoal, gerador do corpo singular, individuado. Em um texto póstumo, Deleuze (1997) associará a potência e efetuação singularizante do corpo à expressão "uma vida" ou, como a conceberemos mais adiante, ao "viver" (em oposição à "vida boa").

No campo intensivo e impessoal, o corpo alcançaria não a sua conciliação consigo mesmo - tal como no sonho metafísico de um corpo desvelado originalmente unitário -, mas uma consistência, isto é, um povoamento e distribuição de forças situacionais, em uma fusão disjuntiva de multiplicidades. "Um Cs0 é feito de tal maneira que só pode ser ocupado, povoado por intensidades" (DELEUZE; GUATTARI, 1996, p. 13).

Deleuze e Guattari, assim como Artaud, declaram guerra às estratégias que tentam traduzir esse coletivo (isto é, o campo intensivo, os diversos agenciamentos que perfazem o $\mathrm{Cs} 0$ ) em um Uno, seja na forma humanizada de uma consciência constituinte ou de uma subjetividade transcendental. Esse inimigo, dizem eles, chamase organismo.

Percebemos pouco a pouco que o Cs0 não é de modo algum 0 contrário dos órgãos. Seus inimigos não são os órgãos. 0 inimigo é 0 organismo. 0 Cs0 não se opõe aos órgãos, mas a essa organização dos órgãos que se chama organismo [...] 0 organismo não é 0 corpo, 0 Cs0, mas um estrato sobre o Cs0, quer dizer um fenômeno de acumulação, de coagulação, de sedimentação que the impõe formas, funções, ligações, organizações dominantes e hierarquizadas, transcendências organizadas para extrair um trabalho útil (BIDEM, p. 21).

Os organismos criam sedentarizações totalitárias (códigos, religiões, moralidades, valores, etc.), fazem acreditar que um limite (Cs0), tal como um 
apocalipse, é o fim do mundo, pois faz coincidi-lo com o próprio organismo.

A guerra do Cs0 contra o organismo, no entanto, deve ser ponderada, bem feita. "Não se atinge 0 Cs0 e seu plano de consistência desestratificando grosseiramente" (Ibidem, p. 23). Deve-se saber ministrar essa tensão, "abrir 0 corpo às conexões que supõem todo um agenciamento, circuitos, conjunções, superposições e limiares, passagens e distribuições de intensidades, territórios e desterritorializações" (Ibidem, p. 22). Em outras palavras, desfazer (e não matar) o organismo.

A operação do $\mathrm{Cs} 0$ a partir do distanciamento de seus duplos - corpos vítreos esvaziados (quando a desestratificação/dessubjetivação se dá de modo a desenhar o CsO, mas tornando impossível o seu povoamento) e corpos cancerosos, totalitários e fascistas (quando a desestratificação se dá por um processo descontrolado e mortal) - exige prudência, vigilância da própria composição, justamente para não se tornar organismo. Nesse sentido, mais do que se entregar ao CsO, advertem Deleuze e Guattari, deve-se saber povoá-lo com intensidades, fazer com que elas se distribuam e circulem, mas, também, saber interditar a sua proliferação quando o seu povoamento totalitariza 0 corpo.

Eis então 0 que seria necessário fazer: instalar-se sobre um estrato, experimentar as oportunidades que ele nos oferece, buscar aí um lugar favorável, eventuais movimentos de desterritorialização, linhas de fuga possíveis, vivenciá-las, assegurar aqui e ali conjunções de fluxos, experimentar segmento por segmento dos contínuos de intensidades, ter sempre um pequeno pedaço de uma nova terra. É seguindo uma relação meticulosa com os estratos que se consegue liberar as linhas de fuga, fazer passar e fugir os fluxos conjugados, desprender intensidades contínuas para um CsO (lbidem, p. 24).

Conduzido empiricamente a uma efetuação histórica, o processo bem feito de criação e povoamento de um $\mathrm{CsO}$ pode levar aquele que 0 engendra a novas configurações sociais e subjetivas. Contudo, não se deve idolatrá-lo, mas guardar dele sempre um distanciamento, trazer consigo "um pequeno pedaço de uma nova terra" em cada territorialização, uma contraefetuação para cada plano de povoamento do corpo.

\section{Corpus}

0 seriado TWD, produzido pelo canal de televisão por assinatura AMC, estreou nos EUA no dia 31 de outubro de 2010 pela Fox International Channel. Desenvolvido por Frank Darabont, o seriado televisivo baseou-se no enredo das histórias em quadrinhos de mesmo nome, elaboradas por Robert Kirkman, Tony Moore e Charlie Adlard (Image Comics). Há diferenças entre a versão impressa e a audiovisual - a exemplo da presença de personagens importantes como Daryl, e do rumo tomado em cada narrativa -, razão pela qual optamos por uma das versões.

Em sua estreia nos EUA, TWD registrou um 
público de 5,3 milhões de espectadores. ${ }^{3}$ Hoje, este número vem crescendo, superando, a cada nova temporada, seus recordes anteriores ${ }^{4}$.

Entre os 120 países que veiculam a série, está o Brasil, onde a popularidade da temática zumbi tem aumentado nos últimos anos, em consequência também de eventos culturais como passeatas (Zombie Walk, Dia-Z) e intervenções visuais (cartazes, grafites, etc.).

Para a presente análise, foram considerados os 67 episódios compreendidos desde a primeira até quinta temporada.

\section{Arqueologia do futuro}

A estratégia de análise aqui empreendida pode ser denominada como "mapeamento do presente pelo futuro". A ideia, originária dos modelos de análise literária de György Lúkacs e Fredric Jameson, os quais, segundo Kellner, "tentavam iluminar o presente apresentando uma visão crítica do passado", é por ele adaptada para identificar, em gêneros literários como o cyberpunk, os discursos sociais da atualidade, porém através da imaginação de uma sociedade distópica. dispõem de um rico material descritivo capaz de revelar dramas existenciais e conflitos sociais de nossa época, pois nelas se antevê a prática dos discursos hoje existentes. Nas palavras do autor, essa estratégia "ilumina o presente projetando as visões do futuro que realçam fenômenoschave do momento atual e seus possíveis efeitos" (KELLNER, 2001, p. 401).

Essa estratégia torna-se pertinente à leitura do seriado TWD, pois, assim como no modelo de análise para as obras cyberpunks, muda-se o lugar (contexto) da narração (espaço, tempo, actantes), mas não da enunciação - intertextualidade fundamental à produção sócio-histórica de sentido -, considerando-se, portanto, "as estruturas, as tendências e a dinâmica do presente" que, muitas vezes, atuam aí de modo prescritivo.

Explorar as atuais tendências tecnológicas, culturais e sociais para possíveis resultados futuros é algo que ajuda os indivíduos a mapearem as suas atuais constelações sociais e a desenvolverem a capacidade de enfrentar 0 choque do futuro, uma vez que este inevitavelmente baterá de frente contra nós (KELLNER, 2001, p. 402).

Desse modo, 0 apocalipse zumbi, que em TWD compõe o seu pano de fundo, atualiza um conflituoso conjunto discursivo (posições-

Para Kellner, as narrativas ambientadas no futuro

Disponível em: <http://veja.abril.com.br/blog/temporadas/series-anos-2010-2019/the-walking-dead-estreia-em-120paises-incluindo-o-brasil/>; <http://www1.folha.uol.com.br/ilustrada/2010/11/824113-the-walking-dead-estreia-comrecorde-de-audiencia-nos-estados-unidos.shtml>. Acesso em 14 jun. 2015.

De acordo com a empresa Nielsen Company, que mede a audiência de programas de TV nos EUA, a estreia da quinta temporada de TWD teve uma audiência média de 17,3 milhões de pessoas, superando o seu último recorde, 16,1 milhões, referente ao início da quarta temporada. Disponível em <http://cultura.estadao.com.br/noticias/televisao,thewalking-dead-bate-recorde-de-audiencia,1576575>. Acesso em 15 jun. 2015. 
sujeito) que, de nós, exige hoje uma decisão. Em sua extensão infinita, 0 apocalipse corresponde a um Cs0 pleno, uma forma-vazia ou puro devir: ele porta a profusão infinita de relações e modos de vida que, em geral, são interditados por dispositivos sociais disciplinares de nossa época (família, comunidades de personalidades coletivas, etc.). Um cenário tanto confuso para a liberação dos desejos, quanto propício para comportamentos fóbicos e obsessivos.

Teixeira destaca, neste ambiente, uma fantasia comum do sujeito do desejo que, afinal, encontraria um mundo perfeito, sem Estado, lei ou instituições:

[...] a ideia de que pessoas comuns, cuja vida se divide entre 0 trabalho cansativo e a rotina entediante, encontram no fim do mundo a chance de iniciar uma vida nova, diferente e emocionante. Para tais sujeitos, o mundo devastado pela guerra nuclear ou por um ataque de zumbis não é um cenário depressivo, e sim entusiasmante (TEIXEIRA, 2013, p. 14).

Essa fantasia é a mesma vivida pelos survivalists, construtores de bunkers (fenômeno comum nos EUA), para quem a longa estiagem da raça humana já começou. Sendo real (posto que praticada), a fantasia deve, no entanto, ser mediada por uma estrutura mínima de sentido capaz de projetar alguma inteligibilidade sobre os corpos desejantes ${ }^{5}$. Neste caso, propõe-se aqui uma linha tênue entre o Cs0 pleno e o organismo. Essa composição permite-nos não só analisar este corpo em sua dinâmica subjetiva, mas 0 sutura também em dois planos de manifestação e observação: 0 individual (na relação entre uma consciência/subjetividade e suas adjacências) e o coletivo (na relação entre as constituições das consciências/subjetividades e 0 social).

No plano individual, a plenitude do CsO comparece no assédio multidimensional sobre a consciência dos personagens. Ressalta-se que a presença deste $\mathrm{Cs} 0$ na trama de TWD singulariza-o no interior do gênero, já que 0 desenrolar subjetivo de seus personagens está sob frequente abalo, em um jogo de profundidade e superfície, de flutuações identitárias e digressões que comprimem ou expandem violentamente 0 espaço cênico. É por essa razão, diz Teixeira (2013, p. 13), que "[...] na maior parte do tempo dos episódios da série TWD, a ação cede lugar à exploração da intimidade dos personagens, seus conflitos, suas dúvidas e seus medos". 0 zumbi não está apenas lá fora, mas preexiste no corpo incubado, metaforicamente, na forma de um vírus que abre imensas fissuras, revogando a segurança ontológica dos personagens quando esses recuam para conciliar-se consigo mesmo: quem é Daryl, Andrea, Tyreese...? Subjetivamente, essas narrativas de si são perturbadas por composições interiores performadas por limiares.

"Corpos desejantes" não se refere aqui apenas aos survivalists, mas a todos que alimentam alguma fantasia no apocalipse. Como veremos a seguir, a organização proposta entre $0 \mathrm{Cs} 0$ e 0 organismo permite compreender tais survivalists como corpos esvaziados ou mortais. 
Suas "histórias" ou dramas pessoais são sempre coletivos, um encontro de pessoa e zumbi no esforço impraticável de purificação.

Em oposição a tal instabilidade subjetiva, comparecem os organismos que atuam, em grande parte do tempo, como crivos. 0 primeiro é Rick, ex-xerife de uma pequena cidade da Geórgia. Conhecemos toda a história do seriado a partir dele; sua aparição coincide com a própria consciência narrativa que vai organizando o fluxo de acontecimentos em uma estrutura parcial de sentido. Logo no início, Rick acaba com a dispersão do grupo (estimulada por Merle, Ed e Shane), dele fazendo emergir uma organização moral fundada na sobrevivência. Posteriormente, acoplam-se a ele outros organismos: Hershel, cuja autoridade mantida pelo que ainda resta de respeito à tradição garante, temporariamente, a canalização de desejo do grupo às produções sociais úteis (divisão do trabalho, agricultura, casamento, religião, pilhagens, etc.), além de Michonne, ex-advogada, que alcança autoridade semelhante através do medo, do terror e da violência.

Se o destino dos personagens de TWD é incerto, tampouco é conhecida a sua origem. Se eram casados ou tinham filhos, se eram ricos ou religiosos, se tinham um sobrenome, etc., esses qualificativos são apenas passagens; têm pouca relevância para uma série que opera por acontecimentos: surgimento e desaparição repentina de pessoas e memórias. Tais personagens apresentam-se como andarilhos, corpos que perderam seu organismo (lar, família, amigos, profissão, eu, etc.). Alguns, obsessivos, consomem a sua existência tentando encontrá-lo em uma nova terra; outros, abandonam a esperança de qualquer retorno, cura ou recompensa, adaptando-se melhor ao apocalipse. Não à toa que Glenn, um habilidoso batedor (adestrador de fluxos, especialista em passagens e fugas), e Daryl, personagem plano, de subjetividade vazia, tenham aí se destacado a ponto deste último ganhar uma zona intensiva própria no game "The Walking Dead Survival Instinct".

Carol encontra-se também neste coletivo. Após perder seu organismo (lar, marido e filha), passa a vagar como um zumbi entre os humanos. Ela reproduz a instância máxima da superficialidade subjetiva: pálida, magra, fria, sem emoção, 0 mundo escorrega por seu corpo.

0 fato de todos os personagens terem perdido seus organismos não implica uma reterritorialização sempre problemática. É verdade que a sua perda viabiliza o povoamento do corpo que o torna, amiúde, inabitável (como em Rick e Sasha). Entretanto, se alguns seguem a linha alucinada do apocalipse, outros perseveram na segurança de suas casas ou comunidades. 0 problema está em colocarse neste limite do organismo, estacionar, tal como o faz o grupo de Rick, na fronteira entre a sedentarização e o nomadismo, lugar de efervescência de conflitos subjetivos (ponto 
alto do seriado) e, portanto, da tensão entre uma sobrevida (recuar ou se entregar ao $\mathrm{Cs} 0$ ) e a sua liberdade (manejar e empreender as reterritorializações infinitas do Cs0). A decisão de sempre ignorar esse limite, de amaldiçoar tal Cs0, evitando empreendê-lo para além dele, é o que definirá cada um como sobrevivente.

Essa tensão é encontrada também em seu nível coletivo, isto é, no âmbito dos agrupamentos humanos. Aqui, a disputa é ainda a mesma (organismo x CsO, comunidade x social), mas agora enfocada nas atividades em comum. No decorrer das temporadas, o conflito entre estes vários coletivos (zumbi, indivíduos, grupos, etc.) intensifica-se, comparecendo as comunidades como instâncias disciplinares e totalizadoras da profusão descontrolada destes corpos sob intensa relação - Cs0 pleno, corpos vítreos esvaziados, corpos cancerosos e totalitários, etc. - quais sejam: o acampamento e 0 Centro de Controle de Doenças (CDC) em Atlanta; a fazenda de Hershell; a Prisão; a Igreja e Alexandria.

Em TWD, essas comunidades compõem platôs de desaceleração, zonas de intensidades mínimas ou abrigos temporários à "caótica antiestrutura zumbi" - termo apropriado de Veloso (2013), referente à presença dos zumbis na organização (social) humana ${ }^{6}$. Dessa "antiestrutura", as comunidades podem extrair não só uma produção útil (ferramentas, técnicas de cultivo, pastoreio e medicalização, estratégias de guerra, fuga e captura, etc.), mas a própria vida, isto é, o "entusiasmo" do apocalipse, dada a infinitude de seu caráter sociabilizador, fonte de inesgotável perigo à comunidade e, portanto, de constantes elaborações, reinvenções e cuidado de si.

0 paradoxo destas comunidades, entretanto, é que, à custa da conservação da vida, seus integrantes são forçados a eliminarem a própria vida: em Alexandria, Carl diz ao pai que a fortaleza pode enfraquecê-los e matá-los; no grupo formado por Carol, Tyreese e as irmãs Lizzie e Mika, Carol não tem problema em revelar 0 assassinato da namorada de Tyreese ou eliminar a pequena Lizzie por elas oferecerem perigo à comunidade - essa última por brincar na perigosa fronteira entre 0 abrigo subjetivo e a antiestrutura zumbi.

Embora apresentados como coincidentes pelo seriado, sobreviver e viver revelam-se, aos poucos, como modos de sociabilidade distintos. Enquanto o primeiro se refere a um bastarse a si mesmo, a um encontro harmonioso na memória, na tradição ou na fantasia

"Nos produtos midiáticos com a temática zumbi, emerge o drama social pela sobrevivência dos dois grupos, zumbis e alguns poucos sobreviventes humanos. Há conflitos entre eles, mas há conflito também nos pequenos grupos de humanos que ainda se referenciam por meio de uma estrutura, ainda que em desestruturação, por uma caótica antiestrutura zumbi. Nesse limiar os grupos de humanos repensam suas estratégias e as reorganizam para sobreviver" (VELOSO, 2013, p. 182). 
(mesmo na compulsão ${ }^{7}$ ) de si ou do grupo; 0 segundo evoca a abertura ao desconhecido e à potência desbravadora de si, a partir de interdições necessárias ao refreamento da máquina desejante, extraindo deste jogo a sua singularização. Em TWD, os personagens não procuram uma tal vida; caem nela acidentalmente ou são forçados a atravessá-la. Desmotivados, dedicam-se ao fortalecimento de muros, à separação dos estranhos (ou mesmo à aniquilação deles), à restauração do antigo mundo (alimentado pelo sonho obsessivo do grupo de chegarem a Washington D.C.). Diversamente, encontram na vingança alimentada pelo ressentimento, nas ações reativas e repetitivas, a sua força e entusiasmo. Quando emergem os conflitos, retornam para si ou para aquilo que os põem em comum: reexistir neste modo de vida.

As comunidades em TWD são, sobremaneira, autocêntricas e mortais; exterminam a possibilidade de sua singularização e do indivíduo singular. Quando a comunidade de Rick chega à Prisão e se depara com um grupo de detentos, Rick propõe um modo de convivência baseado na separação dos grupos em alas carcerárias, em uma vida comunitária fundada em fronteiras intransponíveis. 0 mesmo acordo, posteriormente, será firmado com 0 Governador. 0 contrato aí oferecido - que, para muitos, parece razoável - revela o limite de uma sociabilidade que tem na separação a resposta para a convivência. Pressupostos comuns, e que se revelam no seriado, são de uma alteridade parasita e contraproducente, apresentada nas figuras do psicopata ou do oportunista, os quais devem ser sempre evitados (ou eliminados); e de uma única forma de acolhê-los, isto é, submetendo as suas diferenças à moral da comunidade, tornando-os úteis à sobrevivência.

No Terminus, quando Rick e seu grupo são capturados por uma comunidade de canibais - uma forma intensificada de organismo -, Carol, impassível, surge da floresta para salválos. Durante o confronto com Carol, Mary (mãe de Gareth, líder dos canibais) revela: "Os sinais... eles eram reais, era um santuário. Pessoas vieram e tomaram este lugar. E eles estupraram, e eles mataram. Eles riram... durante semanas. Mas nós nos libertamos, nós lutamos e tomamos este lugar de volta. Nós escutamos a mensagem! Você é o açougueiro... ou você é o gado"s. Nas paredes do local onde 0 confronto se desenrola, estão as frases:

"Nunca confie. Nós primeiro, sempre". ${ }^{9}$

"The signs... they were real, it was a sanctuary. People came and took this place. And they raped, and they killed. They laughed... over weeks. But we got out, and we fought and we got it back! And we heard the message! You're the butcher.. or you're the cattle".

9 "Never Trust. We First, Always". 
Tais frases reiteram 0 ideário personalista comunitário de Rick. De fato, a partir do Terminus, sua comunidade assumirá um intimismo mais ostensivo, aumentando o consenso na desconfiança do Outro e no fechamento e interiorização (dessingularização) de seus membros. Nenhum comportamento esquivo, nenhuma brincadeira, nenhuma produção que não seja voltada à sobrevivência passará impune pela vigilância da comunidade.

A insistência do Cs0 sobre a formação subjetiva dos personagens e de suas comunidades remetenos ao questionamento casual que fazemos aos organismos de nossa vida social: 0 destino do andarilho solitário não seria preferível a um comunitarismo inquisidor? Se nossos corpos já estão todos infectados, então como abraçarmos este mundo, não como o melhor dos mundos, mas como o único que nos resta (obviamente, não em nome do triunfo do Cs0, mas do fim de um sobrevivencialismo entediante)?

\section{Comunidade das singularidades nômades}

Através da proposta teórico-metodológica de Kellner (o mapeamento do presente pelo futuro), procuramos evidenciar em TWD a questão do sobrevivencialismo contemporâneo manifesto em dois níveis de observação, 0 individual e 0 coletivo. Gostaríamos, portanto, de encerrar 0 texto com duas reflexões sobre 0 tema, porém, sem a pretensão de esgotá-las aqui.
A primeira diz respeito à relação entre obra e público. Ou melhor, à maneira como o público participa da série televisiva garantindo sua audiência, popularidade e, evidentemente, novas temporadas. Essa participação, segundo Kellner, é fundamental para inferências sobre a cultura contemporânea, já que 0 tecido constitutivo das práticas sociais está hoje visceralmente preso aos conteúdos midiáticos.

Retomamos aqui a mesma estratégia de Teixeira, qual seja, acompanhar a série não a partir dos zumbis, mas dos humanos que fogem deles: "Como 0 espectador geralmente se identifica com os personagens humanos, interessa pensar qual a atitude e a motivação de tais personagens, como eles se situam no mundo". Assim, poderíamos indagar: estariam os fãs de TWD ansiosos por uma avalanche derradeira que dividiria Rick e seu grupo, ou mesmo que os enterrassem para sempre? Ou, do contrário, estariam eles seduzidos pela sobrevivência, torcendo pela restauração das antigas instituições, autoridades ou mesmo fantasias de uma dominação (seja na figura de um louco, ou de um comedor de gente) que, ao menos, garantiria algo para depois (ainda que o mesmo) desta dialética?

Tal indagação não pode ser respondida definitivamente, porém, evidências como a própria construção da trama que modula suas temporadas, com ápices de carnificina sobre os grupos alheios ao de Rick - assim como as linhas de força dos fãs que vibram pela permanência 
de personagens e do grupo -, sugerem que tal sobrevivência ainda se arrastará por muito tempo.

A segunda questão se refere à tensão discursiva que delimita o sobrevivencialismo como modo de sociabilidade da cultura contemporânea, caracterizado pelo vínculo com o mesmo, fundamento das comunidades de personalidade coletiva, e que se expressa no material analisado. ou seja, qual força ou prática discursiva que se lhe opõe e que, no limite, poderíamos empreendêla para contraefetuá-lo. Se, através da série, conhecemos o comportamento apropriativo do dispositivo humano sobre a "antiestrutura", então, como enfrentá-la com dignidade, isto é, sem conjurá-la em nome de nosso conforto subjetivo, ou apenas para a nossa sobrevivência, mas para além de "uma vida boa"?

A resposta pode ser buscada na advertência de Deleuze e Guattari para uma ação prudente de povoamento do corpo. Desfazer 0 sobrevivencialismo (e não matá-lo).

A partir da terceira temporada, os zumbis passam a ser um problema menor de Rick e sua comunidade. 0 desafio agora é encarar os próprios humanos com suas manias e obsessões, com suas ocupações intensivas e sufocantes: a moral e a culpa corrosiva de Rick, as fantasias pervertidas do Governador, a esperança desesperada de Abraham. Uma ação bem feita, nestes casos, prescreveria a abertura do corpo e o seu esvaziamento, gesto que se apresentaria no acolhimento dos estranhos e de suas vicissitudes, nas divisões internas do grupo ou em seu próprio abandono, na supressão da espera e do próprio corpo cancerígeno.

Ora, não se trata aqui de uma hospitalidade divina equilibrada com doses de violência mundana, mas de contraefetuar o humano em uma situação extrema, entre humanos: tornar-se errante, passível de toda suscetibilidade e indeterminação, quando o demasiadamente humano avança sobre o corpo; mas também saber evocar o organismo, quando tais desestratificações fogem do controle - buscar um distanciamento da máquina esvaziadora e mortífera, estabelecendo modos de convivência para otimização da vida.

Se uma vida não vale mais do que qualquer outra, se na guerra do corpo uma perda faz-se inevitável na batalha entre 0 CsO e 0 organismo, a escolha de uma vida faz-se por aquela que não domestica, apequena, elimina ou arrasta outras vidas, mas que se oferece à com-vivência e ao cuidado pela libertação de muitas outras.

Da correlação entre a antiestrutura zumbi e a vida comunitária, portanto, evidenciase precisamente "uma vida", não a vida boa (satisfatória e segura), mas a vida para além da mera sobrevivência, lapidada na singularidade de uma experimentação. Sugerimos aqui o termo "comunidade de singularidades nômades" a essa forma limítrofe de sociabilidade que se dá no fazer, na experiência singular de uma errância. Trata-se 
de uma comunidade incomum porque impessoal e fundada, paradoxalmente, na singularidade dos corpos individuais e coletivos, na imprevisibilidade do livre trânsito de sujeitos e comunidades, uma comunidade de solitários solidários abertos ao encontro e à dessubjetivação, às destruições e reconstruções recíprocas de valores; enfim, baseada na produção comum da vida para a sua potência singularizante.

Essa comunidade comparece em nossa vida cotidiana de maneira neutra e impessoal, por isso, muitas vezes, apenas passa, despercebidamente. Como no seriado, sua presença no humano é fugaz e, por vezes, impensada, como na vez em que Daryl e Hershel tentam dividir, respectivamente com Martinez e Milton, um maço de cigarro e informações médicas, enquanto Rick e 0 Governador travam uma batalha psicológica; ou ainda na vida solitária-solidária de Morgan, ou na voluntariosa desestratificação derradeira de Merle para a queda do corpo cancerígeno de Woodbury.

Instalar-se sobre tal comunidade torna frustrante a pretensão de apego a certo personagem, a tarefa de entendê-los em profundidade, ou mesmo de justificar, por artifícios lógicos, o próprio apocalipse zumbi. Neste momento, o sobrevivente torna-se singularidade: colocando-se no olho do apocalipse, aceita com serenidade a fuga permanente que este platô lhe oferece. Reiterando Deleuze e Guattari, "ao Cs0 não se chega" quando perguntamos o que é, já estamos sobre ele.

\section{Referências}

AGAMBEN, G. 0 que é o contemporâneo? e outros ensaios. Chapecó: Argos, 2009.

BAUMAN, Z. Comunidade: a busca por segurança no mundo atual. Rio de Janeiro: Jorge Zahar, 2003.

BECK, U. Sociedade de risco: rumo a uma outra modernidade. São Paulo. Ed. 34, 2011.

DELEUZE, G. A imanência: uma vida... In VASCONCELLOS, J; FRAGOSO, E. A. R. (Orgs.).

Gilles Deleuze: imagens de um filósofo da imanência. Londrina: Eduel, 1997, p. 15-19.

DELEUZE, G.; GUATTARI, F. Mil platôs: capitalismo e esquizofrenia, v. 03. São Paulo: Ed. 34, 1996.

GIDDENS, A. As conseqüências da modernidade. São Paulo: Ed. Unesp, 1991.

GONZALO, J. F. Filosofía zombí. Barcelona: Editorial Anagrama, 2011.

KELLNER, D. A cultura da mídia. Bauru: Edusc, 2001.

SENNETT, R. 0 declínio do homem público: as tiranias da intimidade. São Paulo: Companhia das Letras, 1995.

TEIXEIRA, M do R. Por que será que gostamos tanto dos filmes de zumbi? Cogito, Salvador, v. 14, p. 12-15, 2013.

VELOSO, S. C. B. Performances culturais: a invasão zumbi, a morte do sujeito e outras desorientações. Visualidades, Goiânia, v. 11, n. 01, p. 173-187, 2013. ZIZEK, S. Bem-vindo ao deserto do real! São Paulo: Boitempo Editorial, 2003. 
The Walking Dead: survivalism, body without organs and community of nomadic singularities

\section{Abstract}

From the theoretical and methodological proposal of Douglas Kellner (the mapping the present from the future), the TV series The Walking Dead (2010$2015 \ldots$...) is analyzed as a discursive support that presents a subjective tension in mediatized cultures from the US. Two premises subsidize this work: the inseparability between the mediated culture and the contemporary social practices and; the presence of different forms of sociability in this culture: close to the binding profusion of today or expose to a subjective experience. To assist the analysis, we use the concept of "body without organs", from Artaud, Deleuze and Guattari.

\section{Keywords}

Media culture 1. Zombie philosophy 2.

Discourse analysis 3.
The Walking Dead: survivalismo, cuerpo sin órganos y comunidad de singularidades nómadas

\section{Resumen}

A partir de la propuesta teórica y metodológica de Douglas Kellner (cartografiando del futuro al presente), se analiza la serie de televisión, The Walking Dead (2010-2015...), como soporte discursivo de una tensión subjetiva en las culturas mediatizadas de los EE.UU. Dos premisas subsidiam este trabajo: la inseparabilidad entre la cultura mediatizada y las prácticas sociales contemporáneas y; la presencia de regímenes divergentes de sociabilidad en esta cultura: cerrarse a la profusión vinculativa de hoy 0 exponerse a la experimentación subjetiva. Para ayudar con este análisis, se utiliza el concepto de "cuerpo sin órganos", de Artaud, Deleuze y Guattari.

\section{Palabras clave}

Cultura mediática 1. Filosofía zombi 2.

Análisis del discurso 3. 


\section{Expediente}

A revista E-Compós é a publicação científica em formato eletrônico da Associação Nacional dos Programas de Pós-Graduação em Comunicação (Compós). Lançada em 2004, tem como principal finalidade difundir a produção acadêmica de pesquisadores da área de Comunicação, inseridos em instituições do Brasil e do exterior.

\section{E-COMPÓS I www.e-compos.org.br I E-ISSN 1808-2599}

Revista da Associação Nacional dos Programas de Pós-Graduação em Comunicação.

Brasília, v.18, n.2, maio/ago. 2015.

A identificação das edições, a partir de 2008, passa a ser volume anual com três números.

Indexada por Latindex I www.latindex.unam.mx

\section{CONSELHO EDITORIAL}

Alexandre Rocha da Silva, Universidade Federal do Rio Grande do Sul, Brasil Alexandre Farbiarz, Universidade Federal Fluminense, Brasil Ana Carolina Damboriarena Escosteguy, Pontifícia Universidade Católica do Rio Grande do Sul, Brasil

Ana Carolina Rocha Pessôa Temer, Universidade Federal de Goiás, Brasil Ana Regina Barros Rego Leal, Universidade Federal do Piauí, Brasil André Luiz Martins Lemos, Universidade Federal da Bahia, Brasil Andrea França, Pontifícia Universidade Católica do Rio de Janeiro, Brasil Antonio Carlos Hohlfeldt, Pontifícia Universidade Católica do Rio Grande do Sul, Brasil

Arthur Ituassu, Pontifícia Universidade Católica do Rio de Janeiro, Brasil Álvaro Larangeira, Universidade Tuiuti do Paraná, Brasil Ângela Freire Prysthon, Universidade Federal de Pernambuco, Brasil César Geraldo Guimarães, Universidade Federal de Minas Gerais, Brasil Cláudio Novaes Pinto Coelho, Faculdade Cásper Líbero, Brasil Daisi Irmgard Vogel, Universidade Federal de Santa Catarina, Brasil Daniela Zanetti, Universidade Federal do Espírito Santo, Brasil Denize Correa Araujo, Universidade Tuiuti do Paraná, Brasil Eduardo Antonio de Jesus, Pontifícia Universidade Católica de Minas Gerais, Brasil

Eduardo Vicente, Universidade de São Paulo, Brasil

Elizabeth Moraes Gonçalves, Universidade Metodista de São Paulo, Brasil Erick Felinto de Oliveira, Universidade do Estado do Rio de Janeiro, Brasil Francisco Elinaldo Teixeira, Universidade Estadual de Campinas, Brasil Francisco Paulo Jamil Almeida Marques, Universidade Federal do Ceará, Brasil Gabriela Reinaldo, Universidade Federal do Ceará, Brasil Gisela Grangeiro da Silva Castro, Escola Superior de Propaganda e Marketing, Brasil

Goiamérico Felício Carneiro Santos, Universidade Federal de Goiás, Brasil Gustavo Daudt Fischer, Unisinos, Brasil

Herom Vargas, Universidade Municipal de São Caetano do Sul, Brasil
Itania Maria Mota Gomes, Universidade Federal da Bahia, Brasil Janice Caiafa, Universidade Federal do Rio de Janeiro, Brasil Jiani Adriana Bonin, Universidade do Vale do Rio dos Sinos, Brasil José Afonso da Silva Junior, Universidade Federal de Pernambuco, Brasil José Luiz Aidar Prado, Pontifícia Universidade Católica de São Paulo, Brasil Kati Caetano, Universidade Tuiuti do Paraná, Brasil

Lilian Cristina Monteiro França, Universidade Federal de Sergipe, Brasil

Liziane Soares Guazina, Universidade de Brasília, Brasil Luíza Mônica Assis da Silva, Universidade de Caxias do Sul, Brasil Luciana Miranda Costa, Universidade Federal do Pará, Brasil Malena Segura Contrera, Universidade Paulista, Brasil Marcel Vieira Barreto Silva, Universidade Federal da Paraíba, Brasil Maria Ogécia Drigo, Universidade de Sorocaba, Brasil Maria Ataide Malcher, Universidade Federal do Pará, Brasil Maria Clotilde Perez Rodrigues, Universidade de São Paulo, Brasil Maria das Graças Pinto Coelho, Universidade Federal do Rio Grande do Norte, Brasil

Mauricio Ribeiro da Silva, Universidade Paulista, Brasil

Mauro de Souza Ventura, Universidade Estadual Paulista, Brasil

Márcio Souza Gonçalves, Universidade do Estado do Rio de Janeiro, Brasil Micael Maiolino Herschmann, Universidade Federal do Rio de Janeiro, Brasil Mirna Feitoza Pereira, Universidade Federal do Amazonas, Brasil Nísia Martins Rosario, Universidade Federal do Rio Grande do Sul, Brasil Potiguara Mendes Silveira Jr, Universidade Federal de Juiz de Fora, Brasil Regiane Ribeiro, Universidade Federal do Paraná, Brasil Rogério Ferraraz, Universidade Anhembi Morumbi, Brasil Rose Melo Rocha, Escola Superior de Propaganda e Marketing, Brasil Rozinaldo Antonio Miani, Universidade Estadual de Londrina, Brasil Sérgio Luiz Gadini, Universidade Estadual de Ponta Grossa, Brasil Simone Maria Andrade Pereira de Sá, Universidade Federal Fluminense, Brasil Veneza Mayora Ronsini, Universidade Federal de Santa Maria, Brasil Walmir Albuquerque Barbosa, Universidade Federal do Amazonas, Brasil

\section{COMISSÃO EDITORIAL}

\section{Cristiane Freitas Gutfreind}

Pontifícia Universidade Católica do Rio Grande do Sul, Brasil

\section{Irene Machado}

Universidade de São Paulo, Brasil

Jorge Cardoso Filho

Universidade Federal do Reconcavo da Bahia, Brasil

Universidade Federal da Bahia, Brasil

\section{EQUIPE TÉCNICA}

ASSISTENTE EDITORIAL I Márcio Zanetti Negrini

REVISÃO DE TEXTOS I Press Revisão

EDITORAÇÃO ELETRÔNICA I Roka Estúdio

CONTATO I revistaecompos@gmail.com
COMPóS I www.compos.org.br

Associação Nacional dos Programas de Pós-Graduação em Comunicação

Presidente

Edson Fernando Dalmonte

Programa de Pós-Graduação em Comunicação

e Cultura Contemporânea - UFBA

edsondalmonte@uol.com.br

Vice-presidente

Cristiane Freitas Gutfreind

Programa de Pós-Graduação em Comunicação Social - PUC-RS cristianefreitas@pucrs.br

Secretário-Geral

Rogério Ferraraz

Programa de Pós-Graduação em Comunicação

Universidade Anhembi Morumbi

rogerioferraraz@anhembimorumbi.edu.br 